\title{
Evaluation of Crude Yam Starch from White Yam (Dioscorea rotundata poir.) as a Pharmaceutical Excipient in Tableting of Paracetamol
}

\author{
Daniella Onyeka Awunor ${ }^{1}$, Christianah Yetunde Isimi ${ }^{2}$, Joseph Chukwuebuka Oguegbulu ${ }^{1}$ and Joseph Anireju \\ Lori $^{1^{*}}$
}

${ }^{1}$ Department of Chemical Sciences, Bingham University, Kodape, Karu, Nasarawa State, Nigeria.

${ }^{2}$ Department of Pharmaceutical Technology \& Raw Material Development, National Institute for Pharmaceutical Research and Development, Idu Industrial Area, FCT, Nigeria

Correspondence Author: Joseph Anireju Lori, Department of Chemical Sciences, Bingham University, Kodape, Karu, Nasarawa State, Nigeria.

E-mail: joseph.lori@binghamuni.edu.ng

Received date: 18 March 2019, Accepted date: 26 June, Online date: 29 June 2019

Copyright: $\odot 2019$ Daniella Onyeka Awunoret al, This is an open-access article distributed under the terms of the Creative Commons Attribution License, which permits unrestricted use, distribution, and reproduction in any medium, provided the original author and source are credited.

\begin{abstract}
Starch is a widely available natural macromolecule which is used among other things, as a pharmaceutical excipient. In the formulation of solid oral dosage forms of drugs as tablets, it works mainly as a binder. Corn starch BP is widely used in pharmaceutical formulations. Yam starch has also been well reported. The aim of this study was to utilise starch extracted from locally sourced white yam (Dioscorea rotundata poir) as a pharmaceutical excipient in the formulation of paracetamol tablets and hence evaluate its binding properties in comparison to corn starch. Iodine test and Molisch test were used to confirm the extracted yam starch. The active pharmaceutical ingredient (API) was confirmed to be Paracetamol BP via chemical tests, FTIR and comparison to a standard. The physicochemical properties of the starch were evaluated using standard methods and machinery. Three batches each (YS1, YS2 and YS3 for yam starch binder and CS1, CS2 and CS3 for corn starch binder) of 300mg paracetamol tablets (250mg API) with increasing binder concentrations $(5 \% \mathrm{w} / \mathrm{w}, 7.5 \% \mathrm{w} / \mathrm{w}$ and $10 \% \mathrm{w} / \mathrm{w}$ respectively) were made for each binder and tablet properties were compared. The yield of extracted yam starch was $61 \%$ with an average particle size of $14.6 \pm 2.43 \mathrm{~mm}$.The micrometric studies of the yam starch indicated good flow character and compressibility index witha bulk density of $0.65 \pm 0.00004 \mathrm{~g} / \mathrm{ml}$, tapped density of $0.86 \pm 0.00001 \mathrm{~g} / \mathrm{ml}$, angle of repose of $25.5 \pm 6.9^{0}$, Hausner's ratio of $1.322 \pm 0.00004$ and Carr's index of $24.32 \pm 2.03$. The pre-compression analysis of granules showed excellent granular flow properties, with yam starch slightly better than corn starch. Increasing concentrations of the yam starch binder in the tablets showed an increasing effect on the mechanical strength of the tablets and also led to an increase in the disintegration time of the tablets. Yam starch showed better hardness while the corn starch gave a slightly better friability in the tablets. Results showed that Dioscorea rotundata poir starch had comparable properties to corn starch when used as a tablet binder. There were fairly obvious variations in tablet hardness, friability and disintegration time. Yam starch, when extracted at pharmaceutical grade can therefore be considered an effective and viable alternative binder in the pharmaceutical formulation of tablets. Its concentration in tablets can be optimized depending on the physicochemical properties of other excipients present.
\end{abstract}

Keywords: Pharmaceutical Grade Starch (PGS), Dioscorea rotundata poir, Yam starch, Excipient, Disintegrant, Active Pharmaceutical Ingredient (API), Paracetamol, Binder

\section{INTRODUCTION}

Pharmaceutical excipients are additives used to convert pharmacologically active compounds into pharmaceutical dosage forms suitable for oral administration to patients. Excipients such as tablet binders are used in the formulation of tablets to hold the active pharmaceutical ingredient (API) and inactive ingredients together in a cohesive mix (Colorcon, 2018). Disintegrants, on the other hand, help in the disintegration of the capsule or tablet when introduced to moisture such as a physiological environment. Starch is one of the most abundant biomolecules in nature. It is synthesized in the plastids of plant leaves and stored as an energy storage form in seeds, grains, roots, stems and tubers of most plants. Chemically, it is composed of two polymers: amylose and 
amylopectin. Apart from being a source of carbohydrates in the food, starch is most widely utilized in the pharmaceutical industry in the formulation of solid dosage forms where it serves as a binder and disintegrant. Its usefulness here is due to its relative availability, abundance, pharmacological inertness, low cost, physicochemical properties as well as its renewability and environmental friendliness. Although corn starch is one of the most widely used carbohydrates in tablet formulations, pharmaceutical grade starch (PGS) has also been obtained from various botanical sources including maize, potato, cassava, rice, and yam (Itiola et al., 2005; Hauwa et al., 2016); Emiola and Delarosa, 1981). Starches from different plant sources show variations in the amylose-amylopectin ratio, granule structure, and granule size. Hence, differences in the functional attributes and physicochemical properties of starches depend to a large extent on the plant origin (Ogunwa et al., 2016).

The high starch content of yam tubers ( 70 to $80 \%$ dry weight) has made them a potential source of starch that could be explored commercially (Bharath et al., 2012). Compared to starches from other tuber and root crops like potato (Solanum tuberosum), cassava (Manihot esculenta) and sweet potato (Ipomoea batatas), there is much less information on yam starches. This seriously hinders the further development of yams as sustainable crops for this industrial use (Otegbayo et al., 2014). More than $90 \%$ of global yam production is from the Savannah region of West Africa. Nigeria is the main producer of yams worldwide, producing about 31 million metric tons annually. This accounts for $60 \%$ of the world's yam and is followed by Ghana and Cote d'Ivoire. (Sanusi and Salimonu, 2006). Interestingly, nearly all of the pharmaceutical grade starch (PGS) used by pharmaceutical industries in Nigeria are imported from overseas. This is an unhealthy situation for both the pharmaceutical industry and the economy.

Paracetamol is also known as acetaminophen and is widely used over the counter drug for pyrexia and mild to moderate pain in all age groups. Paracetamol has been in use for the past 60-70 years and ever since aspirin was found to be a causative agent for Reye syndrome in the 1980s; paracetamol has come to stay as the drug of the first choice for fever in children (Kariyawasam et al., 2005).

In this study, starch powder extracted from white yam (D. rotundata) was used in tableting of paracetamol and its pharmaceutical binding properties were investigated and evaluated in comparison with the more widely used corn starch.

\section{MATERIALS AND METHODS}

\section{Materials}

The Active Pharmaceutical Ingredient (API), Paracetamol was obtained from Abumed Pharmaceuticals, Kaduna - Nigeria. The yam starch was extracted from white yam (Dioscorea rotundata poir.) purchased from a local market in Makurdi, Nigeria and authenticated at the Department of Biological Sciences, Bingham University, Karu, Nigeria. The corn starch and other excipients used in the formulation of the tablet granules, and reagents used to identify paracetamol were gotten from the Department of Pharmaceutical Technology and Raw Material Development, National Institute for Pharmaceutical Research and Development (NIPRD), Abuja. Sodium metabisulphite and other reagents used for Molisch test, iodine test, and solubility studies were obtained from the Department of Chemical Sciences Laboratory, Bingham University, Karu, Nigeria. All reagents used were of analytical grade.

\section{Methods \\ Extraction and Isolation of the Yam Starch}

The isolation of the yam starch was done according to the method of Okunlola and Odeku (2011). White yam tubers were washed, peeled, re-washed with distilled water and cut up into small pieces. The pieces were washed with $2 \%$ w/v sodium metabisulphite in distilled water to prevent darkening. They were then milled into a fine paste. The slurry obtained was sieved through a muslin cloth and the filtrate left to settle. The supernatant was decanted at 12-hour intervals, and the starch slurry was re-suspended in distilled water. After 3 days, the resulting starch cake was collected and dried in a hot air oven at $60^{\circ} \mathrm{C}$ for 12 hours. The dried mass was pulverized using mortar and pestle and then screened through a \#120 mesh sieve. The powder was collected, weighed, and stored properly for further use. The percentage yield of the dried yam starch powder was calculated as follows:

$\%$ Yield $=\frac{M 1}{M o} \times 100$

Where; Mo = Weight of yam tubers used

$\mathrm{M}_{1}=$ Weight of dried yam starch obtained

\section{Evaluation of the Yam Starch}

a. Confirmatory Tests

i. Iodine Test

Starch combines chemically with iodine to form a coloured complex which is blue-black. The sample powder was observed when a few drops of iodine solution were added.

\section{ii. Molisch Test}

This is a test carried out to identify carbohydrates. A violet coloured complex (purplish ring) identifies the sample as a carbohydrate. The sample powder was combined with a small amount of Molisch's reagent ( $\alpha$-naphthol dissolved in ethanol) in a 
test tube. After mixing, a small amount of conc. $\mathrm{H}_{2} \mathrm{SO}_{4}$ was slowly added down the sides of the sloping test tube, without mixing, to form a layer. Colour change was then observed.

\section{iii. $\mathbf{p H}$ determination}

$5.0 \mathrm{~g}$ of yam starch was weighed and transferred to a beaker to which $25 \mathrm{ml}$ of freshly boiled and cooled water was added to make a slurry. The slurry was agitated for one (1) minute and allowed to stand for 15 minutes. The pH was determined using an electric $\mathrm{pH}$ meter.

\section{iv. Solubility Studies}

The solubility of the extracted yam starch was investigated in selected solvents like water, ethanol, acetone, and chloroform at room temperature $\left(32^{\circ} \mathrm{C}\right)$.

\section{v. IR Spectral Data Analysis}

An FTIR spectrum of the yam starch was recorded using a Nicolet IS5 FTIR spectrophotometer with KBr windows. The Nujol mull method was used. About 2-5mg of the substance was triturated with mineral oil (Paraffin) to give a creamy paste. A portion of the mull was placed between two $\mathrm{KBr}$ plates for the determination and the spectra recorded.

\section{Physicochemical and Micrometric Studies}

Tests were carried out to determine the physicochemical, flow, and packing properties of the yam starch.

\section{i. Particle Size Analysis(nm)}

The particle size of the yam starch was determined by observing under an optical micro photographic microscope. The particle size of about 40 particles was determined, and the average particle size was determined.

\section{ii. Water Absorption capacity (\%)}

This was carried out by a modification of the method of Abbey and Ibeh (1998). $1 \mathrm{mg}$ of yam starch was placed in a centrifuge tube of known weigh, and $10 \mathrm{ml}$ of water was added. The mixture was stood for 30 minutes and then centrifuged at 1500rpm for another20 minutes. The supernatant was discarded, and the tube with residue was weighed. The weight difference was recorded as the absorption capacity and expressed as a percent of the initial weight of starch.

\section{iii. Swelling Power}

This test was done to investigate the water holding capacity of the starch powder. $5 \% \mathrm{w} / \mathrm{v}$ of starch suspension was prepared at room temperature with shaking for 5 minutes. The sedimentation volume was recorded, and the dispersion was then allowed to stand for 24 hours. The swelling capacity was determined and expressed as a percentage (\%) of the initial volume of starch as follows:

Swelling capacity $=\frac{\mathrm{V} 2}{\mathrm{~V} 1} * 100$

Where $\mathrm{V}_{2}=$ Final volume after 24 hours

$\mathrm{V}_{1}=$ Initial volume occupied by starch

\section{iv. The angle of $\operatorname{Repose}(\theta)$}

This test measures the angle of inclination of the free surface of the powder to the horizontal of the bulk solid pile of the powder. It also indicates inter-particulate friction within powders and characterizes flow behavior. A glass funnel was clamped at $3 \mathrm{~cm}$ above a flat surface. $25 \mathrm{~g}$ of starch powder was transferred into the funnel while the orifice of the funnel was blocked with a thumb. The powder was then allowed to flow by removing the thumb. When the starch powder was emptied from the funnel, the height $(\mathrm{h})$ of the pile and radius ( $\mathrm{r}$ ) of the base were measured and the angle of repose $(\theta)$ calculated as follows: $\theta=\tan ^{-1} \frac{h}{r}$

\section{v. Bulk Density $(\mathrm{g} / \mathrm{ml})$}

To determine the density of the bulk powder, $40 \mathrm{~g}$ of the starch powder was introduced into a $100 \mathrm{ml}$ graduated cylinder, and the volume was noted. The bulk density $(\rho)$ was calculated using the formula:

Bulk density $(\rho)=\frac{\text { Mass of powder }(w)}{\text { Bulk volume }(V b)}$

\section{vi. Tapped Density $(\mathrm{g} / \mathrm{ml})$}

Tap density is an increased bulk density obtained after mechanically tapping a container containing the powder sample. $40 \mathrm{~g}$ of the starch powder was introduced into a $100 \mathrm{ml}$ graduated cylinder. The cylinder was fixed on the Tap Density Apparatus (Stampf Volumeter 2003), and the timer knob was set for 100 tappings. The volume occupied by the powder was noted. After 100 tappings, the final volume was noted. The tap density was calculated as follows:

Tapped density $=\frac{\text { Mass of powder }(w)}{\text { Tap volume }(V t)}$ 


\section{vii. Hausner's Ratio}

Hausner's ratio gives an insight into the degree of densification of powders, which could occur during tableting. It is the ratio of the tapped density to the bulk density of the granules.

Hausner's ratio $=\frac{\text { Tapped density }}{\text { Bulk density }}$

\section{viii. Carr's Index}

Carr's index is used to indicate the compressibility and flowability of a powder. It is the difference between the tap and bulk densities expressed as a percentage of the tapped density.

Carr's Index $=\frac{\text { Tapped density-Bulk density }}{\text { Tap density }} \times 100$

\section{ix. Bulkiness $(\mathrm{ml} / \mathrm{g})$} tablets.

Determination of bulkiness of the powder is very useful to select appropriate dies and punches for the compression of the

Bulkiness $=\frac{1}{\text { Bulk density }}$

\section{Evaluation of Paracetamol \\ Confirmatory Tests}

These tests were carried out according to the British Pharmacopoeia (2013) procedures.

\section{a. Chemical Test}

To $0.1 \mathrm{~g}$ of the sample powder, $1 \mathrm{ml}$ of hydrochloric acid was added. This was heated to boiling for $3 \mathrm{minutes}$, and $1 \mathrm{ml}$ of water was added. The solution was left to cool, and no precipitate was formed. To this solution, $0.05 \mathrm{ml}$ of a $4.9 \mathrm{~g} / \mathrm{l} \mathrm{solution}$ of potassium dichromate was added (to obtain this concentration, $98 \mathrm{mg}$ of potassium dichromate was dissolved in $20 \mathrm{ml}$ of water). After the addition of potassium dichromate solution, the colour change was checked for.

\section{b. IR Spectral Analysis \\ An FTIR spectrum of the paracetamol powder was recorded using a Nicolet IS5 FTIR spectrophotometer.}

\section{Formulation of Tablets}

Granulation: The extracted yam starch or corn starch was formulated as mucilage, added to a dry mix of paracetamol BP powder, avicel and lactose and mixed with a mortar and pestle. This mixture was sieved, dried in a hot air oven and sieved again to obtain granules. The pre-compression analysis was then carried out.

Compression to tablet: Magnesium stearate and talc were added to each set and properly mixed. 300mg of granules were packaged and compressed into tablets using a single punch tableting machine. All tablets were made using the same compression force. After tableting, post-compression tests were carried out.

Mixing formula: Using the wet granulation method, three different batches, (CS1, CS2and CS3) of tablets were prepared using three different respective concentrations $(5 \%, 7.5 \%$ and $10 \% \mathrm{w} / \mathrm{w}$ of the tablet) of the isolated yam starch as a binder. The same was done for comparative study, using corn starch as a binder to preparer batches YS1, YS, and YS3. The concentration of paracetamol BP was kept constant at $250 \mathrm{mg}$ per tablet, while the weight of lactose was varied inversely to binder (yam or corn starch)to achieve a final tablet weight of 300mg. Other excipients (talc, magnesium stearate, and avicel) were kept at their respective constant weights. In total, six batches of paracetamol tablets were formulated, as shown in Table 1 below.

Table 1: Formulation of Paracetamol Tablets

\begin{tabular}{|c|c|c|c|c|c|c|}
\hline Ingredients (mg/Tablet) & YS1 & YS2 & YS3 & CS1 & CS2 & CS3 \\
\hline Paracetamol BP (API) & 250 & 250 & 250 & 250 & 250 & 250 \\
\hline Corn starch (5\%, 7.5\%, 10\%)(Binder) & - & - & - & 15 & 22.5 & 30 \\
\hline Yam starch (5\%, 7.5\%, 10\%)(Binder) & 15 & 22.5 & 30 & - & - & - \\
\hline Avicel (3\%)(Disintegrant) & 9 & 9 & 9 & 9 & 9 & 9 \\
\hline Talc (2\%)(Lubricant) & 6 & 6 & 6 & 6 & 6 & 6 \\
\hline Magnesium stearate (1\%) (Glidant) & 3 & 3 & 3 & 3 & 3 & 3 \\
\hline Lactose(Filler) & 17 & 9.5 & 2 & 17 & 9.5 & 2 \\
\hline Total & 300 & 300 & 300 & 300 & 300 & 300 \\
\hline
\end{tabular}

Where YS = Yam starch (5\%, 7.5\% and 10\% of 300mg for YS1, YS2 and YS3 respectively

CS $=$ Corn starch (5\%, 7.5\% and $10 \%$ of $300 \mathrm{mg}$ for CS1, CS2 and CS3 respectively) 
Citation: Daniella Onyeka Awunor, et al., Evaluation of Crude Yam Starch from White Yam (Dioscorea rotundata poir.) as a Pharmaceutical Excipient in Tableting of Paracetamol. Australian Journal of Basic and Applied Sciences, 13(6): 32-38. DOI: 10.22587/ajbas.2019.13.6.4

\section{Evaluation of Tablets \\ Pre-compression Analyses}

Before compression, the bulk density, tapped density, angle of repose, Hausner's ratio, Carr's index, and bulkiness of the granules described above were determined according to the procedures discussed earlier. The FTIR spectrum of the granules was also taken using a Nicolet IS5 FTIR spectrophotometer.

\section{Post-compression Analyses}

\section{a. Weight Variation Test}

Twenty tablets were randomly selected from each batch and weighed. The average weight was calculated. Tablets were also weighed individually using a digital analytical balance.

\section{b. Hardness Test}

This test determines it evaluates the integrity of the tablet under different conditions. If a tablet is too hard, it may not disintegrate within the required period. And if too soft, it will not withstand handling. Six (6) tablets each were randomly sampled from each batch. Each tablet was held between the edges of the fixed and moveable parts of the Karl Kolb hardness tester. With the pointer at zero, the adjustable knob was then moved slowly till the tablet broke and the value of hardness indicated by the pointer was noted.

\section{c. Friability Test}

This is a method employed to evaluate the mechanical strength of uncoated tablets upon exposure to mechanical stress and attrition, which leads to surface deformation. Six (6) tablets from each batch were weighed. The tablets were then placed in a Roche friabilator and rotated for 4 minutes. The tablets were then removed, de-dusted and weighed. Friability was expressed as a percentage according to the formula:

$$
\% \text { Friability }=\frac{\text { Initial weight }- \text { Final weight }}{\text { Initial weight }} \times 100
$$

\section{d. In-vitro Disintegration Time}

To determine the time taken for the tablets to disintegrate completely, a tablet was placed in each of the six tubes of the Erweka disintegration tester apparatus. The assembly was suspended in water and maintained at a temperature of $37^{\circ} \mathrm{C} \pm 2$ and operated simultaneously. The time taken for the tablets to disintegrate completely was then noted.

\section{RESULTS AND DISCUSSION}

Results from Evaluation of Yam Starch: The average particle size of the isolated yam starch was 14.6mm. The percentage yield of the starch powder obtained from the yam tubers (Dioscorea rotundata poir.) used in this work was $61 \%$. The pH was $6.87 \pm$ 0.07, which agrees with WHO standard values of 6.8 - 7.2 (Malami and Thompson, 2012). A violet coloured complex (purple ring) was obtained from the Molisch test while a blue-black coloration was observed from the Iodine test. Both were positive tests for starch. The IR spectrum of the yam starch obtained from a Nicolet IS5 FTIR machine further confirmed the identity of the yam starch upon comparison to a standard. The starch was found to be insoluble in cold water, ethanol, acetone, and chloroform at room temperature. However, the gel was formed in boiling water.

Confirmatory Test on Paracetamol BP: A violet color which slowly developed upon reaction with standard potassium dichromate and did not change to red confirmed the sample powder as paracetamol. The IR spectral data further confirmed its identity upon comparison to a standard.

Micrometric Studies of Yam Starch: As shown in Table 2 below, the values obtained for Carr's Index and Hausner's ratio of the yam starch (24.32 and 1.322 respectively) indicate that it has passable flow behavior according to standards (Carr, 1965). The angle of repose $\left(25.54^{\circ}\right)$ indicates an excellent flow character.

Table 2: Results from Micrometric Studies of Yam Starch

\begin{tabular}{|c|c|c|c|c|c|c|c|c|}
\hline Parameter* & $\begin{array}{c}\text { Swelling } \\
\text { Power }\end{array}$ & $\begin{array}{c}\text { Bulk } \\
\text { Density } \\
(\mathbf{g} / \mathbf{m l})\end{array}$ & $\begin{array}{c}\text { Tapped } \\
\text { Density } \\
(\mathbf{g} / \mathbf{m l})\end{array}$ & $\begin{array}{c}\text { Carr's } \\
\text { Index }\end{array}$ & $\begin{array}{c}\text { Hausner's } \\
\text { Ratio }\end{array}$ & $\begin{array}{c}\text { Bulkiness } \\
(\mathbf{m l} / \mathbf{g})\end{array}$ & $\begin{array}{c}\text { Angle of } \\
\left.\text { Repose( }{ }^{\mathbf{a}}\right)\end{array}$ & Particle size (Mm) \\
\hline Yam starch & 1.282 & 0.6487 & 0.8573 & 24.32 & 1.322 & 1.542 & $25.54^{0}$ & 14.56 \\
& \pm 0.0002 & \pm 0.0004 & \pm 0.0001 & \pm 2.03 & \pm 0.0004 & \pm 0.0002 & \pm 6.9 & \pm 2.43 \\
\hline
\end{tabular}

*Mean value of at least 3 determinations \pm Standard Deviation

The bulk and tapped densities are parameters used to predict flow properties and compressibilit, which amongst other properties are important in the overall tableting process. The powder flow is critical during tableting as it must flow uniformly into the tablet dies and punches to ensure tablet weight uniformity, consistency, and reproducibility (Fassihi, 1986). These values for 
Citation: Daniella Onyeka Awunor, et al., Evaluation of Crude Yam Starch from White Yam (Dioscorea rotundata poir.) as a Pharmaceutical Excipient in Tableting of Paracetamol. Australian Journal of Basic and Applied Sciences, 13(6): 32-38. DOI: 10.22587/ajbas.2019.13.6.4

the isolated yam starch indicating its flow, packaging, and compressibility index are shown in Table 2. Altogether, the isolated yam starch had good micrometric properties (USP, 2014) and hence will be useful as a binder in the formulation of tablets.

\section{Pre-Compression Results of Granules}

From the results shown in Table 3 below, all granules showed excellent granular flow properties when compared to standards (Carr, 1965). The values for Carr's index and Hausner's ratio for YS1, YS2, and YS3 were even better than those obtained for CS1, CS2, and CS3. From these results, an efficient tableting process was expected and achieved. This suggests that yam starch as a tablet binder may confer flow properties that result in easier tableting process.

Table 3: Results of pre-compression analysis of granules

\begin{tabular}{|c|c|c|c|c|c|c|}
\hline Parameters* & YS1 & YS2 & YS3 & CS1 & CS2 & CS3 \\
\hline \multirow{2}{*}{ Bulk density $(\mathrm{g} / \mathrm{ml})$} & 0.4354 & 0.4668 & 0.4507 & 0.4619 & 0.4800 & 0.4643 \\
& \pm 0.0001 & \pm 0.0004 & \pm 0.0003 & \pm 0 & \pm 0.0004 & \pm 0.0004 \\
\hline \multirow{2}{*}{ Tap density $(\mathrm{g} / \mathrm{ml})$} & 0.4768 & 0.5531 & 0.5035 & 0.5286 & 0.5411 & 0.5317 \\
& \pm 0 & \pm 0 & \pm 0.0001 & \pm 0.0001 & \pm 0.0001 & \pm 0 \\
\hline \multirow{2}{*}{ Carr's index } & 8.67 & 15.61 & 11.11 & 12.60 & 11.28 & 12.67 \\
& \pm 4.0 & \pm 1.3 & \pm 1.4 & \pm 1.6 & \pm 0.02 & \pm 1.3 \\
\hline \multirow{2}{*}{ Hausner's ratio } & 1.095 & 1.185 & 1.117 & 1.144 & 1.127 & 1.145 \\
& \pm 0.001 & \pm 0.0003 & \pm 0.001 & \pm 0.0003 & \pm 0 & 0.0002 \\
\hline \multirow{2}{*}{ Bulkiness } & 2.297 & 2.142 & 2.219 & 2.165 & 2.083 & 2.154 \\
& \pm 0.003 & \pm 0.002 & \pm 0.001 & \pm 0 & \pm 0.001 & \pm 0.001 \\
\hline \multirow{2}{*}{ Angle of repose $(\theta)$} & $33.62^{0}$ & $30.9^{0}$ & $32.6^{0}$ & $30.64^{0}$ & $30.36^{0}$ & $32.88^{0}$ \\
& \pm 3.8 & \pm 4.9 & \pm 1.7 & \pm 1.6 & \pm 0.2 & \pm 1.1 \\
\hline
\end{tabular}

$*$ Mean value of at least 3 determinations \pm Standard deviation

\section{Evaluation of Formulated Tablets:}

a. Weight Variation: The average weights of tablets were very close to the targeted 300mg. Hence, a good weight variation was achieved with a reasonable standard deviation within $\pm 4 \%$ of target. This is within an acceptable range (BP, 2003).

b. Hardness: As expected, the hardness (crushing strength) of the tablets increased with increasing yam starch binder concentration. Hence, the hardness trend was as follows; YS1 < YS2 < YS3. The same trendCS1<CS2, CS3 was also observed for tablets with the more established corn starch binder. Generally, hardness value of between 4 to $10 \mathrm{~kg} / \mathrm{cm}^{2}$ is acceptable for oral tablets. Batches YS1, YS2, CS1 and CS2, fall well within this range. However, batch CS3 fell outside this range and hence this binder concentration would be considered in excess.

c. Friability: With increasing binder concentrations, tablet friability was generally reduced. Tablets from batches YS1 and CS1 with friability values of $5.09 \%$ and $4.80 \%$ respectively underwent the most surface deformation, and this was expected due to their relatively lower binder concentrations. The specifications for acceptable friability is less than or equal to $(\leq) 1 \%$. Batches YS2, YS3, CS2, and CS3, had more acceptable values that were closer to $1 \%$, which is mostly due to their increased binder concentration since. Same compression force was used in making all the batches of tablets.

Table 4: Results from Evaluation of Formulated Tablets

\begin{tabular}{|l|l|l|l|}
\hline Batch & Weight Variation* $\mathbf{( m g )}$ & Hardness* $^{*} \mathbf{( k g / \mathbf { c m } ^ { 2 } )}$ & Friability (\%) \\
\hline YS1 & $296 \pm 11$ & $4.70 \pm 0.3$ & 5.09 \\
\hline YS2 & $297 \pm 6$ & $8.17 \pm 2.2$ & 1.13 \\
\hline YS3 & $302 \pm 9$ & $10.8 \pm 1.1$ & 1.44 \\
\hline CS1 & $300 \pm 5$ & $7.33 \pm 1.5$ & 4.80 \\
\hline CS2 & $301 \pm 10$ & $8.67 \pm 1.1$ & 1.38 \\
\hline CS3 & $303 \pm 6$ & $15.17 \pm 4.4$ & 1.10 \\
\hline
\end{tabular}

* Mean value of at least three determinations \pm Standard Deviation

d. In-Vitro Disintegration Time: The disintegration time of the tablets generally increased with increasing binder concentrations. Batches YS3 and CS3 did not begin to disintegrate within the first 15 minutes at all while the other batches did not disintegrate completely within the 15-minute benchmark according to Ngwuluka et al., (2010). Although this further points to the fact that the starches are strong binders, this delay in disintegration could also have been caused by other factors such as a lack of sufficient disintegrant (avicel) in the tablet granules and high compression force during tableting. This observation could be rectified by modifying the tableting compression force or using higher concentrations of disintegrant in the granule preparation. On the other hand, this property could also be taken advantage of when producing sustained release drugs. Furthermore, extensive processing of the $D$. rotundata starch to yield pharmaceutical grade starch could eliminate the difficulties in disintegration time here observed.

\section{CONCLUSION}

The pharmaceutical binding properties of starch isolated from D. rotundata was here successfully evaluated in the formulation of paracetamol tablets. Increasing concentration of the binder proved to have an increasing effect on the mechanical 
strength of the tablets and hence, their disintegration times. D. rotundata starch was shown to have the excellent physicochemical properties required to serve as an alternative tablet binder to the more established corn starch. With further modifications to either the starch or the processing methods, D. rotundata starch can be optimized as a useful pharmaceutical excipient in the formulation of medicine tablet forms.

\section{ACKNOWLEDGMENTS}

Authors are grateful to Dr. Zach Agbendeh for helping with the yam samples. We also acknowledge the contribution of National Institute for Pharmaceutical Research and Development, Idu Industrial Area, FCT, Nigeria for the laboratory space provided us to carry out this study.

\section{REFERENCES}

Abbey B.W and Ibeh G.O. (1988). Functional properties of Raw and Heat Processed Cowpea. Advanced Journal of Food Science and Technology 2(1): 41-44

Bharath, S., Reddy, P. M., Deveswaran, R., Basavaraj, B.V. and Madhavan, V. (2012). Extraction of polysaccharide polymer from Dioscorea trifida and evaluation as a Tablet Binder. International Journal of Pharmacy and Pharmaceutical Sciences, 4(3), 347-352.

Carr, R.L. 1965. "Evaluating flow properties of solids", Chem. Eng, 72. 163-8.

Colorcon(2018). Tablet Binders and Disintegrants. Retrieved from http://www.colorcon.com/productsformulation/application/binder-disintegrant (Accessed 23rd August, 2018).

Emiola, L.O., and Delarosa, L.C. (1981). Physico-chemical characteristics of yam starches. Journal of Food Biochemistry, 5(2), 115-130.

Fassihi, A., Kanfer, I. (1986). Effect of compressibility and powder flow properties on tablet weight variation. Drug Dev \& Ind Pharm, 12, $11-13$.

Hauwa, H., Laminu, H.H., Falmata, A.S., Bintu, B.P., Chamba, G.M., Babagana, M. and Modu, S. (2016). Studies on the production and evaluation of starch from yam (Dioscorea spp.) and cocoyam (Colocasia esculenta) tubers cultivated in Nigeria. Nutrition Research Article, 3.2, 72-88.

Itiola, O.A. and Odeku, O.A. (2005). Packing and cohesive properties of some locally extracted starches. Tropical Journal of Pharmaceutical Research, 4(1), 363-368.

Kariyawasam, S.H., Nanayakkara, D.N., Mohottiarachchi, M.A.,Nandasena, Y.L. (2005).A descriptive cross sectional study onmothers self-medicating children. Sri Lanka J Child Health;34:7-12.doi.org/10.4038/sljch.v34i1.563

Malami, S. and Thompson I. (2012). Physicochemical analysis of starch extracted from seeds of Faidherbiaalbida.J. Phy. Sci. \& Inn. 4: $36-43$.

Ngwuluka,N. C., Idiakhoa, B. A., Nep, E. I., Ogaji, I. and Okafor, I. S.(2010). Formulation and evaluation of paracetamol tablets manufactured using the dried fruit of Phoenix dactylifera Linn as an excipient. Research In Pharmaceutical Biotechnology; $2(3), 25-32$.

Ogunwa, T.H., Adeyelu, T.T., Fasimoye, R.Y., Oyewale, M.B., Ademoye, T.A., Ilesanmi, O.C., Awe, O.B., Ajiboye, S.A., Oloye, B.O., Sholanke, D.R. (2016) Phytochemical evaluation and in vitro antioxidant status of Clerodendrum volubile (an indigenous medicinal plant). Pak J Pharm Res; 2: 77-88.

Okunlola, A. and Odeku, O.A. (2011). Evaluation of starches obtained from four Dioscorea species as binding agents in chloroquine phosphate tablet formulations. Saudi Pharmaceutical Journal, 19(2), 95-105.

Otegbayo, O.J., Oyi, A.R. and Allagh, T.S. (2014). Comparative binding effects of wheat, rice and maize starches in chloroquine phosphate tablet. Research Journal of Applied Sciences, Engineering and Technology, 1(2), 77-80.

Sanusi, W.A. and Salimonu, K. K. (2006). Food security among households: Evidence from yam production economics in Oyo, Nigeria. Agricultural Journal, 1, 249-253. 